\title{
Percepção dos pais de crianças pequenas sobre o Ensino Remoto e o Estilo Parental assumido durante a pandemia do COVID-19
}

Maria Paula Cavalcanti Carvalho1; Célio Rodrigues Leite²; Débora Quetti Marques de Souza3

\section{RESUMO}

A pesquisa a seguir é fruto de um estudo realizado com cuidadores parentais de crianças com idade da primeira infância que atualmente estão matriculadas na Educação Infantil, sendo esse estudo marcado pela Teoria dos Estilos Parentais direcionada aos respondentes por intermédio das instituições escolares e tem como objetivo principal compreender a percepção dos pais de crianças pequenas sobre o Ensino Remoto e o Estilo Parental durante a atual pandemia. Para a coleta de dados adotou-se um questionário online que contemplou trinta e nove perguntas dirigidas aos cuidadores parentais, inspiradas nos doze princípios da Educação Positiva e contou como amostra de respondentes cento e trinta e seis adultos. A análise de dados foi construída tomando como base a Análise de Conteúdo que provoca a edificação de um estudo que prioriza a categorização e a organização dos dados, os mesmos se mostram como cruciais para a estruturação dos achados. Para a discussão dos dados, elegeu-se como categorias de análise: Professores, Envolvimento dos cuidadores parentais, Criança enquanto estrutura rizomática e Comportamento dos adultos. A pandemia do Covid-19 lançou desafios aos adultos (professores e cuidadores parentais), e ambos tiveram suas atribuições multiplicadas pela sobrecarga que o ensino remoto trouxe, os professores demonstram uma educação firme e gentil pela óptica dos pais, enquanto a família precisa investir mais nas regras e no uso de tempo de qualidade com suas crianças.

Palavras-chave: Estilos parentais. Educação Infantil. Ensino remoto.

\section{INTRODUÇÃO}

Atualmente a educação mundial passa por redefinições em decorrência da pandemia vigente do vírus SARS-CoV-2, causador da doença do COVID-19, que tem colocado a sociedade em sofrimento psíquico em virtude dos números de mortes alarmantes e o Brasil, é um dos países com maior número de casos confirmados e mortes. A Secretaria de Estado da Educação do Distrito Federal (2020) destaca que a conjuntura social imposta pela pandemia do COVID-19 propôs novas mudanças às famílias e à sociedade influenciando, diretamente a escola e as práticas escolares. Tomando-se a Educação Infantil por sua natureza relacional, há questões específicas a serem refletidas pelos professores como: conhecer a realidade das crianças e famílias, saber que os pais não substituem o papel do professor, dialogar sobre como aderir as crianças à tecnologia, pensar em atividades sem sobrecarregar criança e família, facilitar o diálogo entre criança e família, tornar o brincar como a principal atividade das crianças. Diante desse cenário atual, emergiu na educação a propagação do ensino remoto, onde fez com que houvesse novos arranjos na prática educativa. 
A Secretaria de Estado da Educação do Distrito Federal (2020), aponta que esse tipo de ensino se desenvolve a partir do contexto de isolamento social atual, onde o acompanhamento do processo de constituição das aprendizagens das crianças e de seu desenvolvimento ocorre por meio de ferramentas tecnológicas. Recursos esses, que possibilitam as chamadas de vídeo para conversar e interagir, trocar fotografias, áudios e vídeos, bem como propor atividades produzidas pelas crianças. Quanto às famílias que não possuem condições adequadas (falta de dispositivos eletrônicos e acesso à internet) cabe à escola entregar impressas, as atividades que serão trabalhadas de forma online.

O ensino remoto não substituirá o ensino presencial e o estar com o outro, mas pode ser um caminho para que as crianças não se desconectem totalmente da escola, de seus colegas de classe ou de professores, bem como da experiência de aprendizagem. Esse novo formato de ensino não só exige novas habilidades por parte das crianças, mas exige também dos professores um outro modo de ensinar e viver a educação.

O contexto familiar é extremamente relevante para a construção da autoestima, autoconhecimento e saúde mental da criança, sendo inclusive com os pais que esta aprende a lidar com as adversidades do mundo e a enxergar as situações sob determinada óptica. Aos cuidadores parentais não cabem somente suprir as necessidades básicas da criança, eles precisam educá-las de forma a fazer com que desenvolvam autonomia e adaptação em contextos sociais diversos (WEBER, 2017).

Durante o atual cenário da pandemia da Covid-19, a família tem encontrado enfrentamentos que antes nunca foram experimentados, e nesse novo contexto surge uma necessária adaptação ao ensino remoto que permite a segurança da criança diante da propagação do vírus pandêmico. $O$ adoecimento mental que as crianças têm sentido por conta do isolamento social faz com que os pais se preocupem com a modalidade de ensino remoto que não estavam preparados para lidar, bem como as exclusões que esse ensino pode submeter as crianças, pois grande parte da população não desfruta de dispositivos eletrônicos e com acesso à internet. Além disso, muitos pais não sabem como auxiliar no comportamento dos seus filhos para que haja a integração dos mesmos diante das telas. Porém, por mais difícil que isso tudo possa parecer, o ensino remoto pode ser a mola propulsora para uma nova aprendizagem, fazendo com que a criança mantenha a sua ligação com a instituição escolar, cabendo aos pais reinventar-se para que não haja prejuízos emocionais para a criança.

As atribuições dos pais deverão ser sempre as mesmas, pós pandemia, pois sempre haverá mudanças no mundo e não se sabe ao certo o que virá impactar a educação e a aprendizagem das crianças, mas entende-se que independentemente de tempos adversos, o envolvimento dos cuidadores parentais é crucial para o modo como as crianças vão encarar essas rupturas constantes do viver em sociedade. A família mesmo depois da pandemia sempre será o contexto ecológico pelo qual o sujeito em construção poderá recorrer, é o meio familiar que orienta a criança para o bem-estar e lhe ensina a ter resiliência em tempos de crises. As escolas e seus educadores a cada dia se implicam mais para oferecer uma educação de qualidade mesmo à distância, e os professores a cada dia aprendem 
ferramentas diferentes para enriquecer a prática educativa, no sentido de torná-la mais interativa. A práxis pedagógica tem se constituído enquanto devir, ou seja, aberta às possibilidades de mudanças e caminha na edificação não só da aprendizagem dos alunos, mas dos próprios professores que são autores desse fazer que também enriquecem a sua Práxis, e o estilo autoritativo que envolve disciplina e diálogo contribui para uma aprendizagem efetiva (LEITE, 2018).

A maneira como os pais participam na educação das crianças desemboca nos 'estilos parentais' que esses adultos assumem na rotina familiar. Para Weber (2017) e Cartaxo (2016) ter um estilo parental saudável pode fazer com que os filhos assumam determinadas condutas, ou seja, o tipo de postura parental pode favorecer ou não a atitude da criança diante do mundo. Ao se pensar na pandemia atual e na educação remota, pode-se imaginar concomitante os impactos no desenvolvimento que os pais podem provocar de acordo com cada estilo adotado, logo, a escola não pode estar sozinha, mas em conversação com a família das crianças, e essa conversação depende do tipo de posicionamento dos pais que pode ser construtivo ou não. Os impactos gerados pelos estilos parentais, termo empregado pela literatura científica para designar os comportamentos dos pais diante de seus filhos, podem fazer com que a criança avance ou não na experiência educativa a partir do ensino remoto. Por essa razão, a presente pesquisa se faz importante no sentido de ser um instrumento de questionamento e análise da conduta dos pais na interação com seus filhos durante a primeira infância, trazendo nuances sobre o seguinte questionamento: Quais são os estilos parentais na Educação Infantil durante a pandemia?
Seguindo essa óptica, pode-se destacar a disciplina positiva como uma área que também estuda os estilos parentais e uma educação com firmeza e gentileza. De acordo com Nelsen (2016, p. 19) para a disciplina positiva existem três principais abordagens para a interação adulto-criança:

\begin{abstract}
Rigidez - "Essas são as regras que você deve seguir, e essa é a punição que você vai receber por violar essas regras." Crianças não são envolvidas no processo de decisão. Permissividade - "Não existem regras. Tenho certeza de que nós vamos nos amar e ser felizes, e você será capaz de fazer suas próprias regras no futuro." Disciplina Positiva - "Juntos, nós vamos decidir as regras para nosso benefício mútuo. Também vamos pensar juntos nas soluções que nos ajudarão a resolver nossos problemas. Quando eu precisar usar o meu discernimento sem a sua interferência, eu serei firme com gentileza, dignidade e respeito.
\end{abstract}

\section{AMOR INCONDICIONAL E ESTILOS PARENTAIS}

A educação de uma criança exige que os cuidadores parentais tenham amor incondicional, participação e envolvimento diário para dar sustentação à conexão entre o adulto e a criança, não sendo necessário que os pais façam para além do que podem nem mesmo deve-se almejar a perfeição por parte desses. No entanto, o engajamento na educação dos filhos e o desejo de regar uma relação de bem-estar e de reciprocidade é fundamental. Pode-se reafirmar esse conceito com o seguinte pensamento:

Fique sabendo que não é simples e nem fácil educar uma criança. É preciso um 
grande investimento de tempo, energia, autocontrole, paciência, habilidades parentais [...] Mas é uma tarefa absolutamente fantástica. Às vezes, os pais falam em esculpir uma criança do jeito que eles querem, mas não é esse o ponto que quero enfatizar. Os pais e os filhos devem construir uma relação juntos. Você tem um relatório urgente para entregar, precisa colocar a roupa na secadora, ver se tem comida para o almoço, verificar se há comida para o peixinho dourado e ainda ensinar tudo sobre o mundo! Não é preciso ser superpai e supermãe. (WEBER, 2017, p.18)

A criança para ser contemplada por uma educação saudável necessita sobretudo de acolhimento dos seus cuidadores parentais, esses devem amá-la independentemente do seu comportamento, logo, quando pais costumam fazer críticas destrutivas à criança, essa não entende que o adulto está se referindo a seus feitos que Ihes desagradam, mas pelo contrário internaliza a ideia de que seus pais não a amam ou não lhe admiram, por isso a importância de quando o adulto estiver diante do comportamento dos filhos possa fazer críticas construtivas, mas sempre apontando para a atitude da criança. $O$ foco deve ser nas causas e não no problema em si. Weber (2017) ao falar do amor incondicional na educação dos filhos, aponta que essa relação transcende demonstrações de afeto e carinho, mas envolve também aceitar os filhos como eles são, valorizando seus feitos e muitas de suas escolhas, sendo de suma importância separar a pessoa do comportamento e não fazer comparações da criança com outras, não devendo deixar de amar a criança pelo fato do comportamento dela não lhe agradar.

Os estilos parentais são extremamente fundantes do tipo de clima na relação entre cuidadores parentais e crianças, e esses estilos parentais são estruturados a partir da responsividade e exigência dos adultos, havendo quatro tipos entre eles: permissivo, autoritário, negligente

$\mathrm{e}$ participativo/autoritativo ${ }^{4}$, sendo este último o mais adequado e condizente com a educação positiva, porque equilibra afeto e exigência.

Weber (2017) introduz em suas discussões o que vem a ser estilos e práticas parentais, destacando que se caracterizam como estratégias usadas pelos adultos para disciplinar os filhos, elencando que os estilos parentais referem-se a um conjunto de comportamentos e atitudes dos pais que reverberam na construção de determinado clima na relação entre pais e filhos. Esse clima, segundo a autora, pode ser marcado por expressão corporal, tom de voz, bom ou mau - humor, onde a combinação entre responsividade (afeto, envolvimento) e a exigência (regras e limites) inscrevem no adulto um tipo de estilo parental.

Os estilos parentais também podem ser chamados de estilos de lideranças segundo Leite (2018), os estilos de liderança, tomando como base a ideia de Baumrind (1966) e as reflexões de Weber (2017) 
podem ser caracterizados como: estilo de liderança autoritário onde prevalece alta exigência e baixa responsividade; o estilo de liderança permissivo onde os pais se mostram responsivos, no entanto não são exigentes; no estilo de liderança negligente os pais não são responsivos nem exigentes; no estilo de liderança autoritativo há uma combinação equilibrada de responsividade e exigência, e aqui há o monitoramento dos filhos, mas com afetividade por parte dos adultos.

Toda criança precisa ser cuidada envolta de regras e limites, pois a infância é marcada pelo modelo moral dos pais, onde os filhos espelham os comportamentos dos adultos para a sua vida. Sendo assim, se os adultos quando os cuidadores parentais incluem regras e limites na educação dos filhos, esses vão aos poucos se inscrevendo no mundo da disciplina positiva, que nada tem a ver com rigorosidade, pelo contrário, a criança aprende a desenvolver comportamentos saudáveis e se apoia numa rotina de respeito onde prevalece uma relação implicada com as regras de sua família. Assim,

Limites são os fundamentos e a estrutura de uma casa. Sem a base, a casa vai cair, dia mais ou dia menos. Limites e regras são restrições, e restrições também são boas porque dão segurança. Se você está descendo uma escada íngreme, você gosta que exista um corrimão para lhe dar apoio e segurança, não é? Os pais sempre estão ensinando o que os filhos podem e não podem fazer, mas em vez de somente fazer previsões, "você vai cair", diga a regra, "o chão está molhado, ande devagar"; "não ande com a tesoura na mão". Limites dão segurança e confiança a todos e servem para ensinar a vida social, para civilizar: "não atravesse a rua sem um adulto junto"; "não aceite carona de estranhos"; "são dez horas, hora de ir para a cama". (WEBER, 2017, p. 96-97)

Adotar uma rotina composta por regras não é sinônimo de inflexibilidade para com as crianças nem mesmo isso poderá prejudicar o comportamento da mesma, pelo contrário, a definição de regras permite que a criança cresça respeitando os adultos e viva mais plenamente com uma rotina de horários equilibrados.

Seguindo essa mesma ótica sobre estilos parentais, Nelsen (20126, p. 23) aponta os pontos cruciais para firmar a disciplina positiva que corresponde ao estilo parental autoritativo ou participativo. Assim,

1.É gentil e firme ao mesmo tempo?
(Respeitosa e encorajadora) 2. Ajuda as
crianças a desenvolver um senso de
aceitação e importância? (Conexão) 3. É
efetiva em longo prazo? (Punição
funciona em curto prazo, mas apresenta
resultados negativos em longo prazo) 4.
Ensina habilidades sociais e de vidas
valiosas para a formação de um bom
caráter? (Respeito, preocupação com os
outros, resolução de problemas,
responsabilidade, contribuição,
cooperação)

De acordo com Cartaxo (2016) a definição da rotina é fundamental para manter um equilíbrio mental e físico. Esse planejamento definido gera segurança para a criança, principalmente quando é construído em conjunto com a mesma. Ter horários estabelecidos é sinônimo de ordem e organização, estes podem ser modificados de acordo com as mudanças familiares.

A parentalidade positiva demanda dos adultos uma abertura para o estabelecimento 
de tempo dedicado exclusivamente a seus filhos, e isso não se refere ao fato dos pais e/ou cuidadores se inclinarem totalmente para a educação das crianças, logo todo adulto tem muitas atribuições. Porém, ter um tempo dedicado à criança é uma prática parental que requisita rotina para que os momentos entre pais e filhos se inscrevam com efetividade na subjetividade de ambos. Segundo Cartaxo (2016, p.33):

\begin{abstract}
Os adultos precisam usar o tempo com qualidade junto às crianças, devendo separar um tempo do dia para prestar atenção nas mesmas, e esse tempo deve tornar-se um hábito e/ou prática diária, bem como é necessário incluir as crianças nas atividades dos pais, mostrando para a criança o quanto ela é útil, e para ter esse tempo os pais não precisam relegar de suas atribuições, mas administrá-lo para que tenha qualidade.
\end{abstract}

Ser cuidador parental inclui também regar na criança habilidades para a vida, que dentre essas estão as habilidades sociais. A educação positiva está implicada com a inteligência emocional que permite que a criança e o adulto saibam identificar seus estados emocionais como por exemplo, em situações de birra se a criança tiver tais habilidades como por exemplo o autocontrole, poderá ressignificar situações difíceis. Ao trazer a abordagem do cérebro da criança Siegel e Bryson (2015, p. 90-91) afirmam que:

Outra tarefa importante - e difícil - para os pequenos é manterem-se no controle de si mesmos. Assim, precisamos dar-lhes habilidades que os ajudem a tomar boas decisões quando estiverem incomodados. Use técnicas com as quais você provavelmente já está familiarizado: ensine-os a respirar fundo ou contar até dez. Ajude-os a expressar seus sentimentos. Deixe-os bater os pés com força no chão ou socar uma almofada. Você também pode ensinarIhes o que ocorre em seus cérebros quando sentem estar perdendo o controle - e como evitar "abrir a tampa".

Ainda de acordo com a abordagem neurocientífica é possível ensinar as crianças a se comportarem assertivamente nas relações sociais desde a primeira infância, contanto que os adultos reconheçam o cérebro em desenvolvimento de sua criança, bem como a necessidade de estímulos que ele precisa. Siegel e Bryson (2015, p. 91) ainda elucidam que:

\begin{abstract}
Mesmo crianças pequenas têm a capacidade de parar e pensar em vez de machucar alguém com as palavras ou os punhos. Nem sempre tomarão boas decisões, mas quanto mais praticarem alternativas que não sejam partir para o ataque, mais forte e capaz se tornará o cérebro do andar de cima delas.
\end{abstract}

Considerando o que foi apresentado até aqui, a presente pesquisa pretende como objetivo principal compreender a percepção dos pais de crianças pequenas sobre o Ensino Remoto e o Estilo Parental. A pesquisa propõe também analisar as categorias de análise Professores, Envolvimento dos cuidadores parentais, Criança enquanto estrutura rizomática e Comportamento dos adultos enquanto interferentes na aprendizagem de crianças da educação infantil durante o ensino remoto. Buscou-se também entender as relações entre família e escola em tempos de pandemia na educação de crianças; investigar 
os estilos parentais como determinantes na relação da criança no processo de ensino e aprendizagem à distância; e refletir os pilares necessários para a educação positiva de crianças na primeira infância durante o ensino remoto.

\section{METODOLOGIA}

A pesquisa está vinculada ao Grupo Internacional de Pesquisa em Políticas, Práticas e Gestão da Educação (GIPPPGE), na linha de pesquisa Prática Pedagógica, Currículo e Formação de Professores. Os sujeitos da pesquisa foram os pais ou responsáveis de todas as crianças regulamente matriculadas nas redes privadas e públicas do ensino de Educação Infantil e a pesquisa foi de proporção nacional, podendo os respondentes serem de qualquer cidade do Brasil. O questionário construído pelos pesquisadores, se propôs a compreender os estilos parentais na Educação Infantil e seus desdobramentos no ensino remoto e na aprendizagem das crianças em tempos de pandemia. Esse instrumento contemplou 39 perguntas acerca do comportamento de adultos e crianças, afetividade, estabelecimento de regras da rotina das crianças, aprendizagem da criança, estado emocional de crianças e adultos, comunicação entre cuidadores parentais e professores, sendo socializado entre os pais e/ou responsáveis por meios eletrônicos (internet) através do Google Forms.

O instrumento de coleta de dados foi compartilhado de maneira on-line, utilizando de link da plataforma Google Forms, e o acesso para os respondentes foi socializado nas seguintes redes sociais: instagram, whatsapp e facebook. Tais aplicativos serviram de ponte para a comunicação entre pesquisadores e os pais das crianças. De modo a facilitar a aproximação com o público-alvo, junto ao formulário foi enviada uma mensagem escrita como convite para os voluntários que desejassem colaborar com a pesquisa, e para potencializar a divulgação junto ao convite, foram reafirmados os pré-requisitos que os respondentes precisavam ter para participar do estudo, os quais são: ser responsável pela criança, esta precisaria estar na Educação Infantil e vinculada ao ensino remoto durante a atual pandemia. $O$ Termo de Consentimento Livre e Esclarecido (TCLE) foi disponibilizado aos participantes no momento de acesso pelo link fornecido antes do preenchimento do questionário, e assim eles puderam ler as diretrizes da pesquisa bem como ter acesso aos nomes e contatos dos pesquisadores.

Os questionários respondidos serão arquivados, por um período de cinco anos, cujo acesso é permitido apenas ao pesquisador e seus colaboradores envolvidos na pesquisa. O acesso aos formulários é somente para os pesquisadores desse estudo, e os mesmos se mostraram acessíveis e aptos a responder qualquer dúvida do público participante durante todo o processo da pesquisa. Acredita-se que os resultados desse estudo possam ajudar a compreender os estilos parentais na educação de crianças na primeira infância e seus desdobramentos no ensino remoto e na aprendizagem das crianças em tempos de pandemia da COVID19. Dessa forma, sendo possível identificar as manifestações de maior relevância apontadas pelos pais ou responsáveis, e comparar os resultados permitindo realizar correlações entre os problemas apresentados e as dificuldades encontradas, estruturando uma análise que coloque em efervescência as discussões entre família, 
escola e criança a partir das posturas parentais analisadas.

A qualquer momento ocorrendo algum risco não previsível ou constrangimento, o participante poderia interromper seu preenchimento, não havendo nenhum questionamento sobre a decisão tomada pelo participante. Desta forma, os resultados obtidos favoreceram a formulação de referencial teórico, potencializando futuramente políticas públicas na educação e saúde mental, e servindo de mola propulsora para os estudos de educação para a primeira infância, ressignificando o olhar acerca da formação de professores e psicólogos que atuam com crianças de zero a cinco anos.

Os critérios de exclusão foram pais de crianças de idade acima da faixa etária da primeira infância e também pais que não vivenciaram a experiência do ensino remoto dos seus filhos. $O$ questionário ficou aberto para o recebimento de respostas durante o dia 11 de setembro de 2020 até o dia 30 de setembro de 2020. Obteve-se um quantitativo de 148 respostas, por problemas técnicos com o formulário on-line as 12 primeiras respostas foram eliminadas e para a análise manteve-se 136 respostas restantes. É importante pontuar que das 12 respostas que foram excluídas dentre elas estavam 3 que se referiam a três adultos que validaram o instrumento e apontaram o que acharam do questionário. Quatro das cinco regiões geográficas brasileiras tiveram participantes. Em termos de porcentagem no que se refere ao tipo de rede que as crianças estão vinculadas, as respostas pontuaram $56 \%$ na rede pública e $44 \%$ na rede privada. Já a distribuição dos participantes por Estado foi a seguinte: Região Sul (40,45\%), Região Sudeste (15,44\%), Região Centro-oeste
(0,73\%), Região Nordeste (43,38\%), onde apenas a Região Norte não participou.

Quanto à formação acadêmica dos participantes a maior porcentagem com $41,92 \%$ se refere aos adultos com formação superior incompleta, seguido de $21,33 \%$ de adultos com formação superior completa, e com esses dados já é perceptível que a grande maioria dos respondentes possui um nível de escolaridade considerável. Supõe-se que esses adultos por terem a oportunidade de acessar uma universidade e estar mais próximo de muitos conhecimentos, possam ter uma maior familiaridade acerca da parentalidade, e aqui não se tem a ideia de que a escolaridade é determinante do estilo parental, mas que ela pode oferecer possibilidades de acesso ao que é o desenvolvimento de uma criança e suas necessidades para determinados pais que estão expostos a conhecimentos científicos.

Quanto à atual situação pandêmica os resultados demonstraram que $52 \%$ dos participantes disseram ter sido afetados pela COVID-19 e ao se perguntar de que forma a família do mesmo foi afetada percebe-se uma variabilidade de respostas, onde a questão financeira e a saúde mental registraram os maiores números, seguida de desemprego, saúde física e falecimento de alguém da família, embora uma parte considerável não soube responder essa pergunta

Os resultados obtidos permitiram elencar categorias de análise para uma discussão mais aprofundada e sistemática acerca dos achados mais pertinentes que os questionários suscitaram. Bardin (2016) aponta a análise de conteúdo como um procedimento sistemático que envolve préanálise, exploração do material e tratamento dos resultados, essa última engloba os aspectos inferenciais e de interpretação. 


\section{ANÁLISE DE DADOS \\ - PROFESSORES}

Com relação à seguinte pergunta do questionário: Você acha que o/a professor/a proporcionou 0 quê de mais significativo na aprendizagem da sua criança durante a pandemia? A seguir mostra-se as respostas e a quantidade marcada por opção: O carinho e cuidado dos professores têm sido essenciais (41); A atenção dos professores para as dificuldades de aprendizagem do meu filho tem sido muito importante (8); A dedicação dos professores em sempre se comunicar conosco nos dá uma maior segurança diante desse novo ensino (60); os professores têm usado de muita criatividade e isso faz minha criança aprender mais (27).

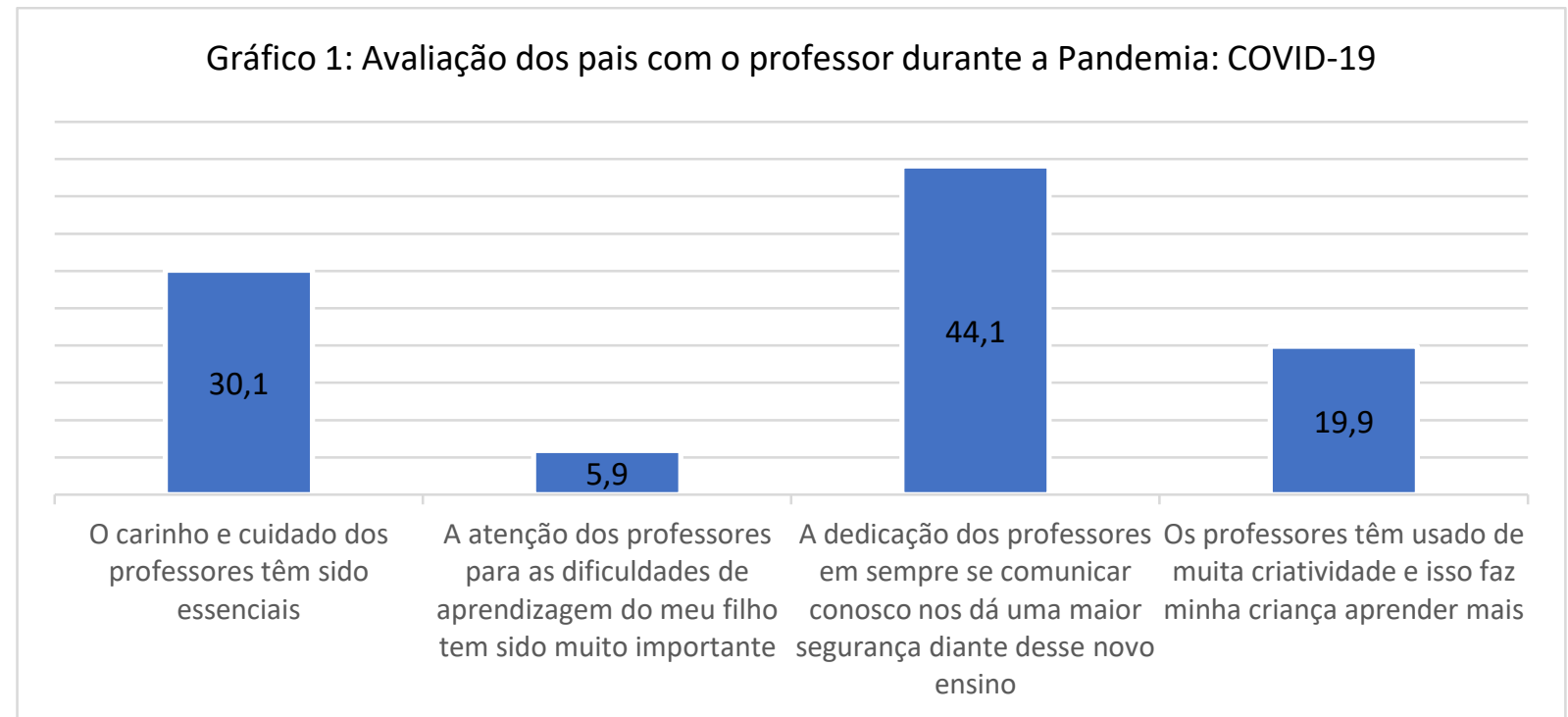

Fonte: (CARVALHO, LEITE e SOUZA, 2021).

A relação professor-aluno é definitivamente determinante para a aprendizagem e bemestar da criança, sabendo-se que há outros fatores que também repercutem para o desenvolvimento escolar da criança como o engajamento da família, dentre outros. No entanto a afetividade do educador e sua forma de comunicação são relevantes no processo educativo. Pode-se afirmar que:

No cotidiano escolar, o relacionamento professor e aluno passa a ser um fator preponderante no desenvolvimento no processo de ensino e aprendizagem. Porém, em determinados momentos, professor e aluno parecem distantes entre si. O professor sente dificuldades em se relacionar com o aluno que por sua vez, pode se tornar um mero receptor de conteúdo, o que nem sempre resulta em aprendizagem significativa. (LEITE, 2018, p.31)

Não somente os cuidadores parentais possuem os estilos parentais, mas há também os chamados estilos de lideranças dos professores, baseados na Teoria dos Estilos Parentais que se assemelham a esses. $O$ estilo de liderança autoritativo permite que o aluno 
seja autor diante do aprender, onde sua voz e modo de pensar é valorizado pelo professor, e este consegue se portar de modo a favorecer à disciplina positiva que nada se assemelha à autoridade. Logo,

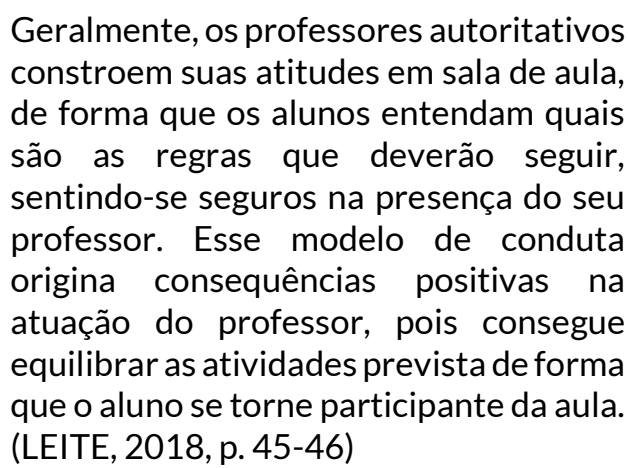

A comunicação do professor com estilo autoritativo é aberta e permeada pelo diálogo e reciprocidade, sempre estando disposta à reflexão por parte dos alunos e é provocadora de questionamentos, permitindo que os alunos e/ou crianças sejam autores no espaço escolar. Leite (2018) reitera que o professor com o estilo de liderança autoritativo firma objetivos para si e para os alunos alcançarem, e regras que são extremamente claras, fazendo com que os alunos reconheçam o que o educador aspira, potencializando a curiosidade e autonomia no processo de aprendizagem.

Ao se referir à pergunta: Como você avalia a dedicação dos professores para com a educação da sua criança durante a pandemia? Com opções de marcar mais de uma resposta nas seguintes sentenças: Os professores trabalham com afinco para o ensino remoto acontecer, (66); Os professores respondem sempre quando nós adultos temos algum problema com as atividades das crianças, (73); Os professores são o maior exemplo de determinação e coragem para a construção da aprendizagem da criança, (61); Considero que há pontos que precisam ser melhorados na relação do educador com o ensino remoto (34), estão pontuados no gráfico 2. Sendo assim, o maior número de respostas está na opção que se refere que o professor sempre estar apto para ajudar os cuidadores parentais com as atividades escolares das crianças.

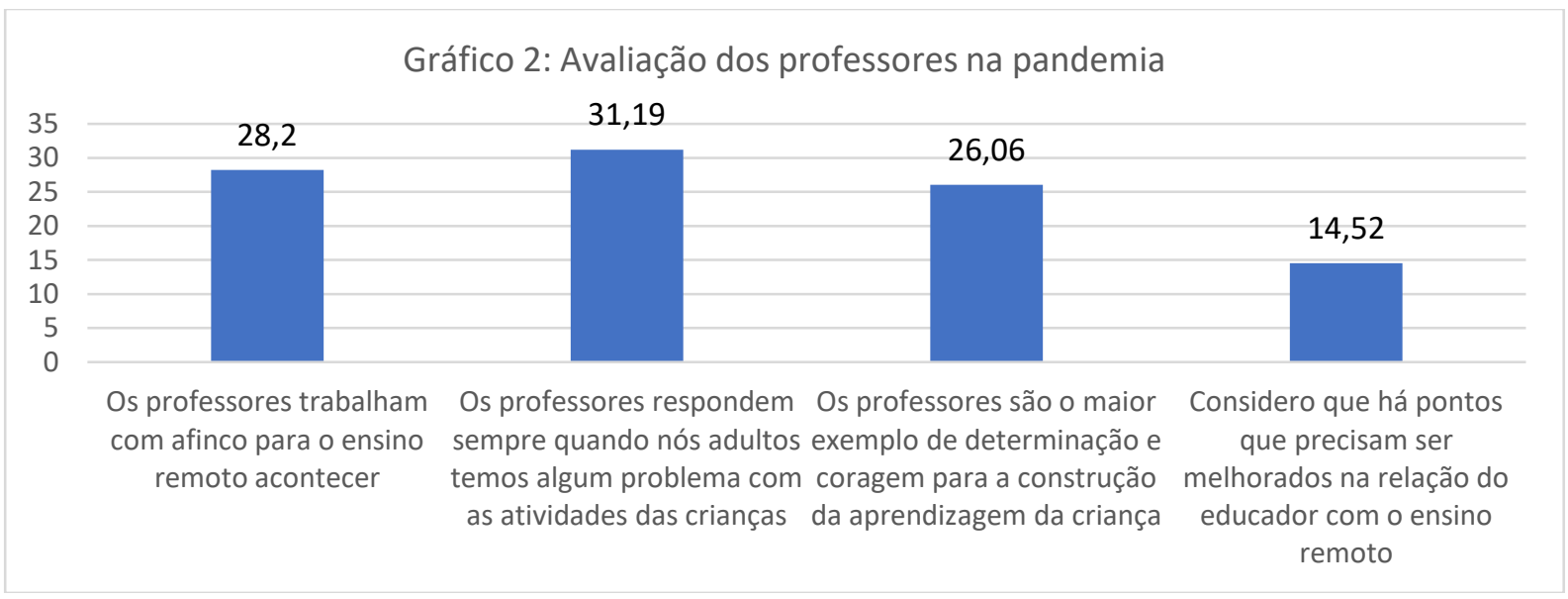

Fonte: (CARVALHO, LEITE e SOUZA, 2021). 
O ensino remoto provocou muitos impactos negativos em crianças, pais e professores, e estes têm aumentado sua jornada de trabalho demasiadamente. Por conseguinte, deve-se destacar que mesmo diante de um cenário tenso de atribuições, os professores têm afirmado sua Práxis com a educação e demonstram a cada dia que passa muito amor e compromisso com o que fazem, deixando que as crianças sejam agentes do processo educativo e procurando sempre se ajustar aos novos tempos que a pandemia suscitou, $\mathrm{e}$ assim percebe-se que esses educadores se assemelham em seu fazer com o estilo de liderança autoritativo. Então,

\begin{abstract}
Estilo de liderança autoritativo é aquele em que o professor combina com as dimensões de responsividade e exigência de forma equilibrada. O professor estabelece limites, regras claras e coerentes e monitora o comportamento dos seus alunos, com afetividade. Realiza atividades que estimulam o aspecto físico, cognitivo, afetivo e social do aluno. Exemplos de professores autoritativos são observados naqueles profissionais que se entusiasmam com as conquistas de cada um de seus alunos, sem discriminá-los, que demonstram paixão pelo que fazem. (LEITE, 2018, p. 45)
\end{abstract}

Um fato que não é possível deixar de falar é que 0 esgotamento emocional dos educadores é uma realidade mundial e o estado psicológico dos docentes se assemelham com a Síndrome de Burnout onde o cansaço mental e físico que o ensino remoto tem alavancado vem ganhando cada dia mais força diante das telas digitais. Portanto,
A síndrome de burnout constitui-se em um dos grandes problemas psicossociais atuais, despertando interesse e preocupação por parte da comunidade científica, entidades governamentais e empresariais. Essa preocupação deve-se ao fato de que o sofrimento do indivíduo acarreta consequências para o seu estado de saúde e prejudica o seu desempenho profissional. (LEITE, 2018, p. 34)

É perceptível como a postura dos professores repercute no aprendizado das crianças na Educação Infantil, no entanto, os resultados acima afirmam que os pais desta pesquisa reconhecem em sua maioria que a Práxis do educador tem sido de encorajamento e de afetividade para com as crianças.

\section{- ENVOLVIMENTO DOS CUIDADORES PARENTAIS}

A seguinte pergunta do questionário foi direcionada aos respondentes sobre o ensino remoto: Como você ajuda/ajudou os professores para a efetivação da aprendizagem da sua criança? Apresentou como seguintes possibilidades de resposta, as quais poderiam ser marcadas mais de uma opção: Eu participo ativamente das atividades que os professores passam para meu/minha filho/a (111); Se minha criança tem alguma dificuldade de aprendizagem que persiste converso com $o$ professor para pensarmos juntos no que podemos fazer (55). No gráfico 3 esses dados são pontuados. 


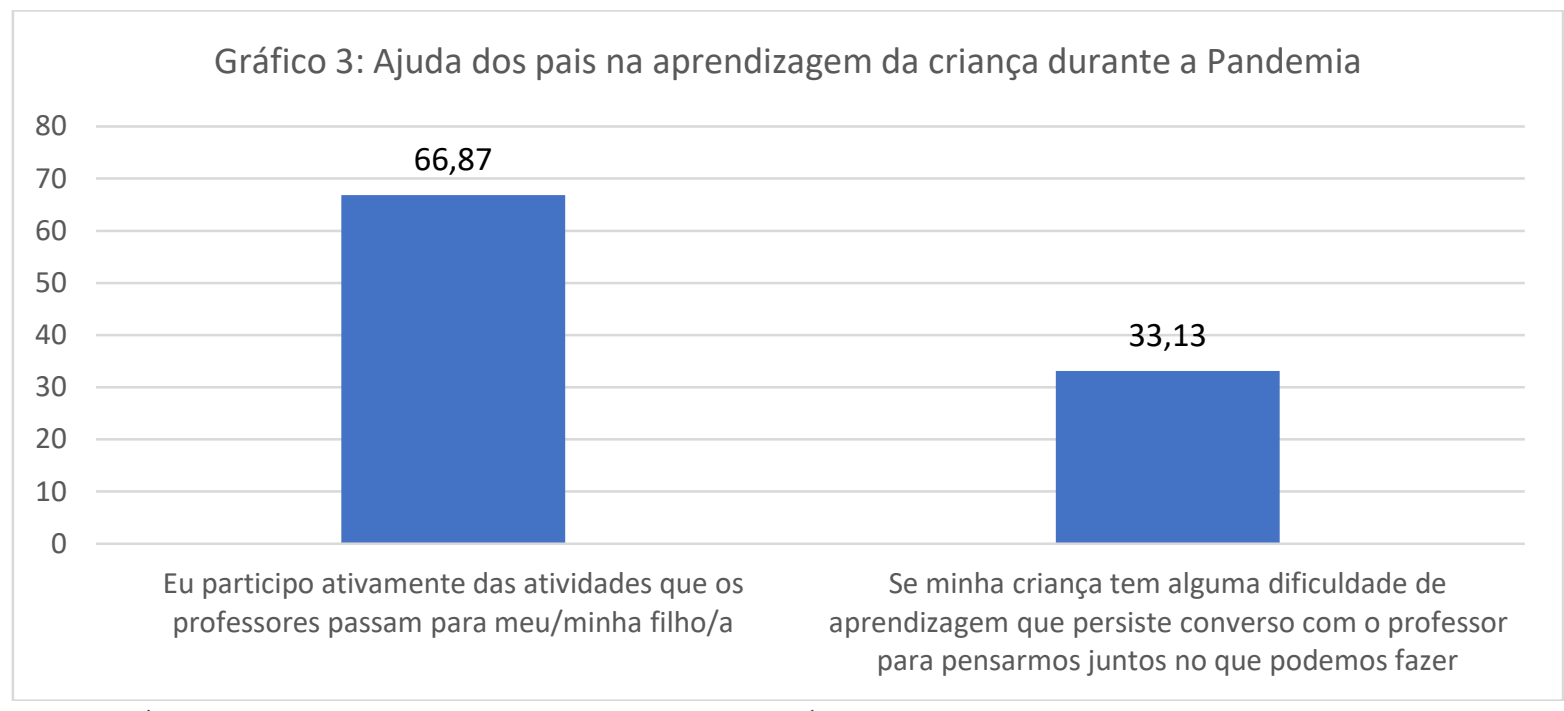

Fonte: (CARVALHO, LEITE e SOUZA, 2021).

Nos dados acima é perceptível que uma grande quantidade dos respondentes acredita que não dedicam tempo suficiente na aprendizagem de seus filhos. A participação e/ou envolvimento dos pais e/ou cuidadores parentais na rotina escolar das crianças repercute no desenvolvimento das mesmas em tempos de pandemia com o novo ensino remoto. O tempo que os adultos dedicam aos filhos requisita que esses cuidadores mergulhem no mundo infantil e conheçam um pouco de tudo o que a criança gosta para uma melhor interação com ela. $\mathrm{O}$ tempo dos pais dedicado às atividades escolares da criança pode edificar momentos prazerosos, devendo-se atentar também para a qualidade de engajamento dos adultos nesses momentos. É importante abordar que:

Os pais, por vezes não entendem o que é "ter tempo" para os filhos ou ter um tempo de qualidade. Pensam que se estão na mesma sala, cada um fazendo alguma coisa diferente, isso é estar junto. Não é. Isso é estar perto. Estar junto é estar engajado em uma mesma atividade e ter interesse verdadeiro pelo que o seu filho está fazendo. Sim, muitas os pais devem aprender a jogar "vídeogame", ou decorar os nomes dos programas favoritos e das centenas de figurinhas que os filhos adoram. Isso significa que os pais não apenas devem tentar que os filhos se interessem pelo que eles fazem e os esportes que praticam, mas viceversa; os pais também devem se interessar pelas escolhas dos filhos. (WEBER, 2017, p. 86)

A pandemia provocada pela COVID - 19 transformou a educação de forma mundial, e assim o ensino remoto trouxe novas nuances para adultos e crianças, e quando se pensa na Educação Infantil que é o recorte da presente pesquisa, entende-se que os cuidados da família devem ser redobrados pelo fato das crianças estarem numa faixa etária da primeira infância, e a educação positiva afirma que, para as crianças serem criadas com saúde mental, é crucial uma participação ativa dos adultos na vida delas como um todo. Weber (2017) aborda que os adultos precisam reorganizar suas prioridades, tendo que muitas vezes renunciar atribuições próprias para cuidar melhor dos seus filhos, 
entendendo que a infância é um período curto da vida de um sujeito, podendo empregar o tempo com qualidade junto às crianças, e essa participação ativa é um fator de proteção para o desenvolvimento psicológico da criança, e favorece envolvimento entre o adulto e a criança.
A pergunta do questionário: Numa escala de zero a 10 quanto de envolvimento você considera ter na educação remota e na aprendizagem do seu filho durante a pandemia? Com as seguintes quantidades de respostas: 0; (1) 1; (2) 2; (0) 3; (4) 4; (5) 5; (14) 6; (8) 7; (15) 8; (33) 9; (18) 10 (36). No gráfico 4 esses dados são detalhados.

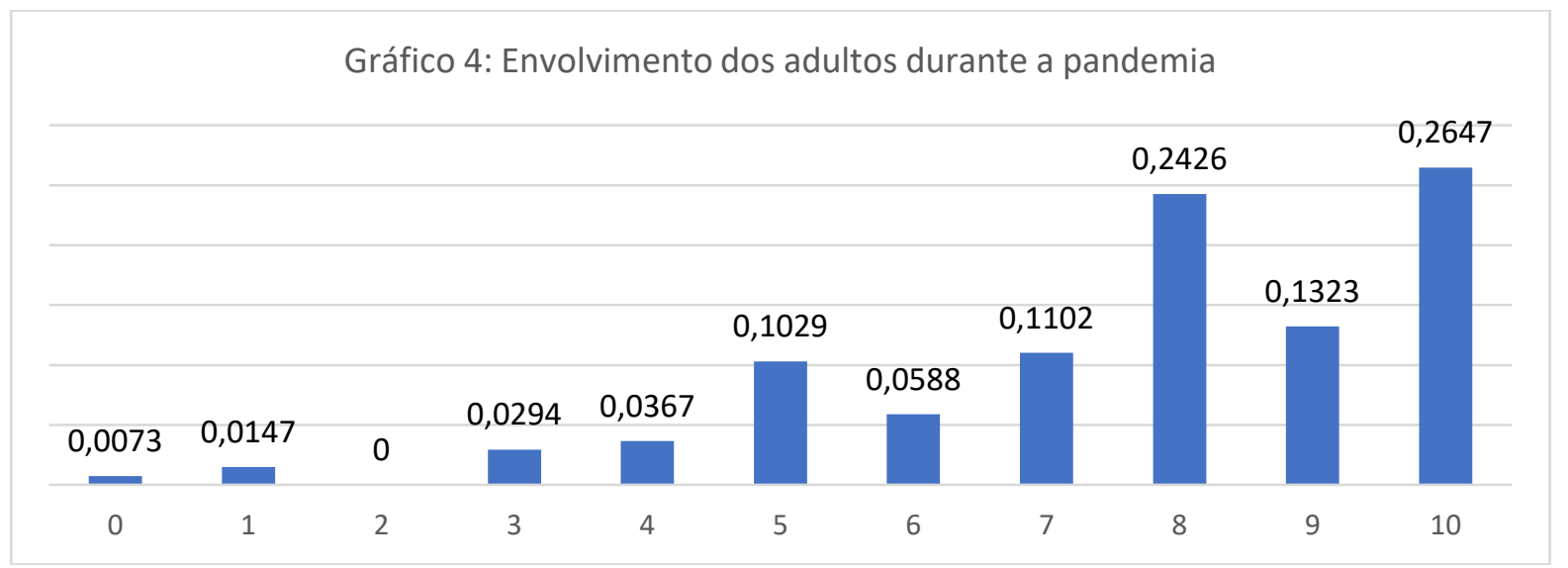

Fonte: (CARVALHO, LEITE e SOUZA, 2021).

Essa questão faz emergir reflexões sobre o tipo de envolvimento e a participação que os adultos têm no mundo das crianças onde apenas 36 participantes marcaram o número 10. Envolvimento exige tempo e atenção, e muitas vezes esse tempo dedicado é usado para diversos interesses dos adultos. Um exemplo é quando os pais colocam suas expectativas nos filhos sem deixá-los serem o que quiserem ser, ou seja, acabam não dando a oportunidade da criança ser ela mesma ou até mesmo falhar e não ser perfeitos, e isso prejudica a autonomia da criança diante do mundo e sua autoestima, concomitante prejudica esse tempo dedicado dos adultos que deveria ser usado com qualidade. É preciso entender que:
Às vezes há pais que participam da vida dos filhos, especialmente em competições, mas demonstram tanto desejo de que o filho seja campeão que chega a ser assustador. Qualquer atividade vira competição, até a feira de ciências, onde os pais extrapolam e mostram comportamento exibicionista nas atividades dos seus filhos. Em uma feira de ciências, que deveria ser montada pelos alunos, cheguei a ver discotecas inteiras armadas, carros importados sendo exibidos...Muito diferente das feiras da minha época em que as crianças criavam seus próprios aparelhos. (WEBER, 2017, p. 84)

Falar da educação das crianças envolve antes de tudo amor incondicional para que os filhos possam se desenvolver com o apoio dos pais, porém que esses adultos não venham a fazer 
tudo por elas, mas que possam instigá-las a ter habilidades de vida diante das adversidades. Ao escrever sobre afetividade e carinho por parte dos pais, Weber (2017, p. 82) traz o seguinte exemplo do filme "Uma lição de amor":

\begin{abstract}
Mas envolvimento significa algo mais do que só estar presente. Em primeiro lugar aparece a Lucy, filha do personagem de Sean Penn. Ela começa a falar de borboletas, ele fica sorrindo para ela; em um momento ela esquece as fases de desenvolvimento da borboleta, o pai não responde, mas diz à plateia, "é que são muitas etapas, não é fácil...". Ela sorri e lembra a outra fase com tranquilidade.
\end{abstract}

Ao adentrar a questão de uma forma geral sobre o universo parental e o envolvimento dos adultos com as crianças, é preciso entender que o relacionamento com essas flui a partir do momento que o cuidador parental se mantém integrado com a criança mesmo quando está fisicamente distante dela por seu dia a dia, e alguns aspectos que os adultos precisam cultivar são sintonia e empatia com seus filhos. Logo:

Conectar-se com os filhos pode ser uma das experiências mais desafiadoras e gratificantes. Os pais têm a possibilidade de construir relacionamentos significativos permanentes com os filhos quando aprendem a desenvolver um senso de junção por meio da comunicação integrativa. (SIEGEL; HARTZZELL, 2020, p. 88).

Assim como os educadores, os pais também tiveram suas atribuições multiplicadas durante a pandemia, e esse novo cenário prejudica o tempo de qualidade que esses adultos passam com as crianças, concomitante o estado emocional dos pais afeta diretamente as crianças, prejudicando sua aprendizagem.

\section{- A CRIANÇA ENQUANTO ESTRUTURA RIZOMÁTICA}

Pergunta do questionário: 0 processo de aprendizagem também é marcado pelas emoções e estado de saúde mental que as crianças estão vivendo. Você acredita que a sua criança apresente. Marque a opção que corresponde a situação psicológica que possivelmente a sua criança esteja passando. Os tipos de respostas e sua respectiva quantidade podem ser descritas como: Ansiedade (49), síndrome do pânico (1), depressão (2), estresse (23), nenhuma das opções anteriores (61). No gráfico 5 a distribuição dessas respostas pode ser analisada. 


\section{Gráfico 5: Processo de Aprendizagem durante a Pandemia}

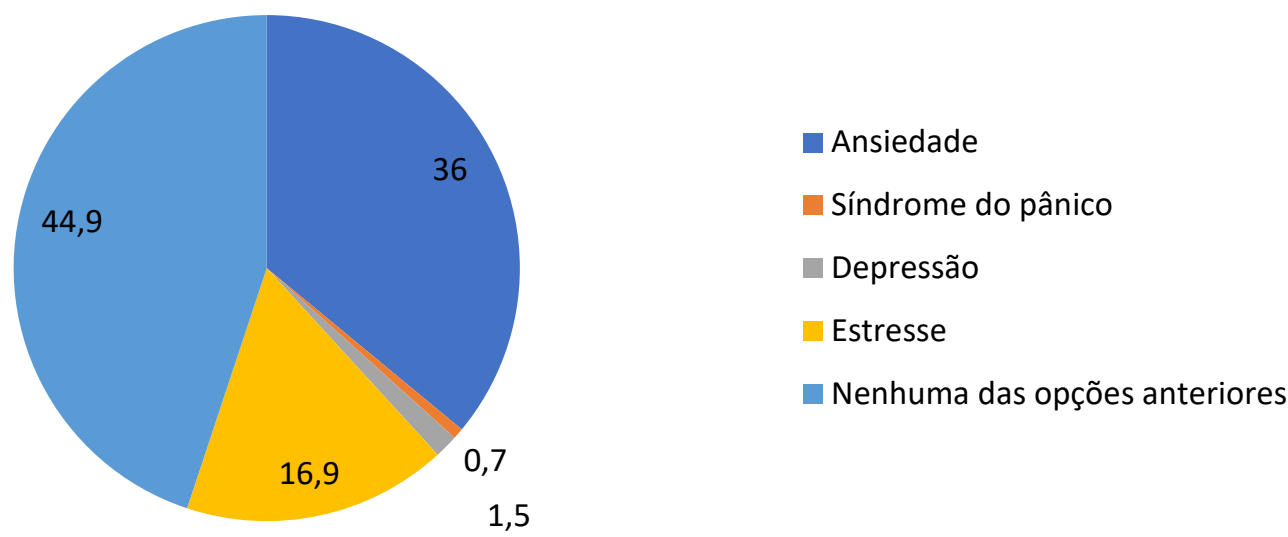

Fonte: (CARVALHO, LEITE e SOUZA, 2021).

A partir das distribuições de resposta quanto a saúde mental das crianças da Educação Infantil em tempos de pandemia percebeu-se que foram marcadas por cuidadores as opções de ansiedade, estresse, depressão e síndrome do pânico, e dentre as opções marcadas ansiedade foi a que mais pontuou. Para a educação positiva é de suma importância que os cuidadores parentais conheçam o desenvolvimento de uma criança e seu estado emocional para que possam contribuir para seu bem-estar e desenvolvimento pleno, e pensando pela via do pensamento rizomático percebe-se que ele se assemelha com o que prega as ideias de parentalidade sobre o que é ser criança, esta não é um vir a ser, ela tem um corpo, apresenta sintoma psicossomático, tem sua subjetividade. Dito de outra forma, não se pode generalizar o que é criança, pois a infância é um processo singular e as emoções desses sujeitos precisam ser percebidas e validadas pelos pais. Então,

\begin{abstract}
Para que se pense a criança e seu corpo a partir do conceito de rizoma é necessário que se pense o corpo para além da simples justaposição de órgãos e suas funções isoláveis. Então, o corpo não é simples matéria, não é passividade diante do mundo: o corpo é condição humana, condição para a vida enquanto existencialidade, é sensibilidade e fluidez, é existência ao mesmo tempo singular e múltipla. (PROBST, 2012, p. 7)
\end{abstract}

A partir das respostas diferenciadas sobre o estado emocional das crianças que seus cuidadores parentais acreditam que elas estão passando durante a pandemia, nota-se que cada criança se revela no mundo de forma singular e a educação positiva mais uma vez comunga dessa ideia. Ao pensar no mundo atual no qual a sociedade está imersa, deve-se ter o devido cuidado para não esvaziar a singularidade das crianças. E assim pensando ainda na estrutura rizomática, elucida-se que: 
Há uma forte tendência do mundo contemporâneo em igualar, ou seja, estabelecer homogeneidades padronizadas, enquanto efeito de uma política de produção em série, em larga escala. Deve-se levar em consideração que muitas vezes o efeito que essa padronização tem é o esvaziamento das singularidades infantis. Na escola, depois de matricular-se, a criança deixa de ser considerada ente singular e torna-se "aluno", uma cópia de um mesmo modelo idealizado. (PROBST, 2012, p. 7)

Nota-se que em relação aos participantes da pesquisa, é possível entender pelas respostas dos cuidadores parentais que cada criança vive nuances singulares quanto ao processo de aprendizagem no ensino remoto, bem como apresenta necessidades específicas, e isso só reafirma como deve-se enxergar a infância em sua pluralidade.

\section{- COMPORTAMENTO DOS ADULTOS}

Pergunta do questionário que teve como enunciado: Explique como você tem administrado seu tempo para auxiliar na aprendizagem da criança durante a pandemia? Foram 136 respostas organizadas nas seguintes categorias: estabelecimento de rotina (65), busca ajuda de terceiros (8), conciliando intervalos de tempo do trabalho (16), organização (7), não tem tempo (12), abdicou do trabalho para se dedicar à criança (1), tem muita disponibilidade (5), criatividade e/ou replanejamento (10), de acordo com as possibilidades (10), está de licença maternidade (2).

Essa questão faz refletir o comportamento dos cuidadores parentais em tempos de ensino remoto, e percebe-se como alguns deles estão inundados pelas atribuições, porém a maior parte dos respondentes afirmam estar usando do estabelecimento da rotina para o manejo da educação de suas crianças, e isso aponta para uma atitude parental assertiva dos adultos. De acordo com Cartaxo (2016) as crianças esperam ansiosas pela chegada dos pais em casa, porque elas querem dividir com eles o que aconteceu no seu dia, e os adultos devem se mostrar dispostos a escutar.

No entanto, para que a rotina seja de fato efetivada os pais precisam associá-la a regras e limites, pois a pandemia segundo muitos relatos dos adultos no questionário, provocou uma desestabilização das regras antes obedecidas pelas crianças. Cartaxo (2016, p. 44) diz que:

É preciso que os pais conversem e estabeleçam os limites sobre o que acham certo e errado, entrando em acordo sobre as regras da casa no que se refere à educação e à rotina. Lembre-se de que a criança testa o tempo inteiro a validade do limite.

A questão, Como você se coloca diante das emoções que sua criança fala ou apresenta em seu comportamento? Marque a opção que mais caracteriza sua conduta de cuidador. A distribuição de respostas foram as seguintes: Se percebo meu/minha filho/a triste sempre procuro conversar com ele/ela; (43) Se minha criança está irritada prefiro deixar ela/ele se acalmar e não converso nada; (1) Quando $\mathrm{meu} / \mathrm{minh}$ a filho/filha me fala de suas emoçõese sentimentos procuro dá toda atenção para que ele sempre converse comigo, pois tudo o que ele sente me importa; (88) Quando minha criança está angustiada ou com algum problema emocional prefiro pedir a ajuda de um outro 
adulto; (1) Não sei lidar com o estado emocional da minha criança (3).

A resposta que mais pontuou foi sobre o fato dos pais dizerem que quando as crianças estão passando por adversidades eles dão atenção e conversam com elas, porque o que suas crianças sentem Ihes importam, e isso demonstra nessa amostra da pesquisa que os adultos caminham para uma educação positiva à medida que validam o estado emocional de suas crianças e reconhecem que mesmo pequenos eles são indivíduos que já são marcados por situações psicológicas adversas. Embora haja momentos de inundação emocional tanto por parte dos adultos como das crianças, cabe aos cuidadores responsáveis saber lidar com as emoções de ambos e deixar claro seu amor pelas crianças. Logo,

A autoestima elevada vem do fato de sermos e nos sentirmos amados, especialmente por aqueles que amamos e que cuidam de nós. Vem do que chamamos de amor incondicional. Em poucas palavras, o seu filho precisa saber que você o ama não importa que erro ele tenha cometido ou o quanto você esteja zangado com ele. Isso não é difícil. É preciso perceber que, ao contrário do que muitas pessoas mal-humoradas falam, "crianças são más por natureza", "crianças só dão trabalho", "você deve aproveitar a vida antes de ter filhos", "crianças provocam os adultos o tempo todo", crianças são seres incríveis, e filhos são melhores ainda. Você não ama o seu filho porque ele é o seu filho e é único. É claro que apenas isso não basta. (WEBER, 2017, p. 25)
E assim é que vai se delineando entre o adulto e a criança um clima de cumplicidade e conexão, onde a inteligência emocional ganha espaço no comportamento dos cuidadores parentais que se mostram prestativos quando acolhem a dor emocional de sua criança.

Weber (2017) destaca que a inteligência emocional na educação dos filhos é imprescindível, porque essa envolve habilidades capaz de fazer com que a criança saiba identificar, descrever e compreender suas emoções, ao mesmo tempo associandoas aos eventos cotidianos, e principalmente quando os pais percebem que as crianças estão sofrendo emocionalmente o ideal é que esses adultos possam validar os sentimentos da criança, tendo com a mesma uma conversa e escuta ativa, e que juntos possam lançar uma reflexão diante do estado emocional da criança construindo um vínculo de cumplicidade.

Com relação à pergunta, A psicóloga Lídia Weber diz que: "Podem haver diferentes regras para adultos e crianças, isso é evidente, mas os pais devem cumprir regras também" Se você concorda com essa afirmação, descreva quais atitudes dos pais ajudam para uma educação positiva? Foram cento e trinta e seis respostas organizadas nas seguintes categorias: fortalecer a espiritualidade da criança (2), respeito (11), dar exemplo e/ou ser um modelo moral (32), escutar e/ou compreender a criança (13), manter a rotina (9), regras e limites (21), diálogo (3), coerência (6), evitar brigas e não bater (1), afetividade (9), ter disciplina (3), não adotam regras e/ou discordam (3), não soube responder (1), responderam apenas sim (2), ser participativo (20). 


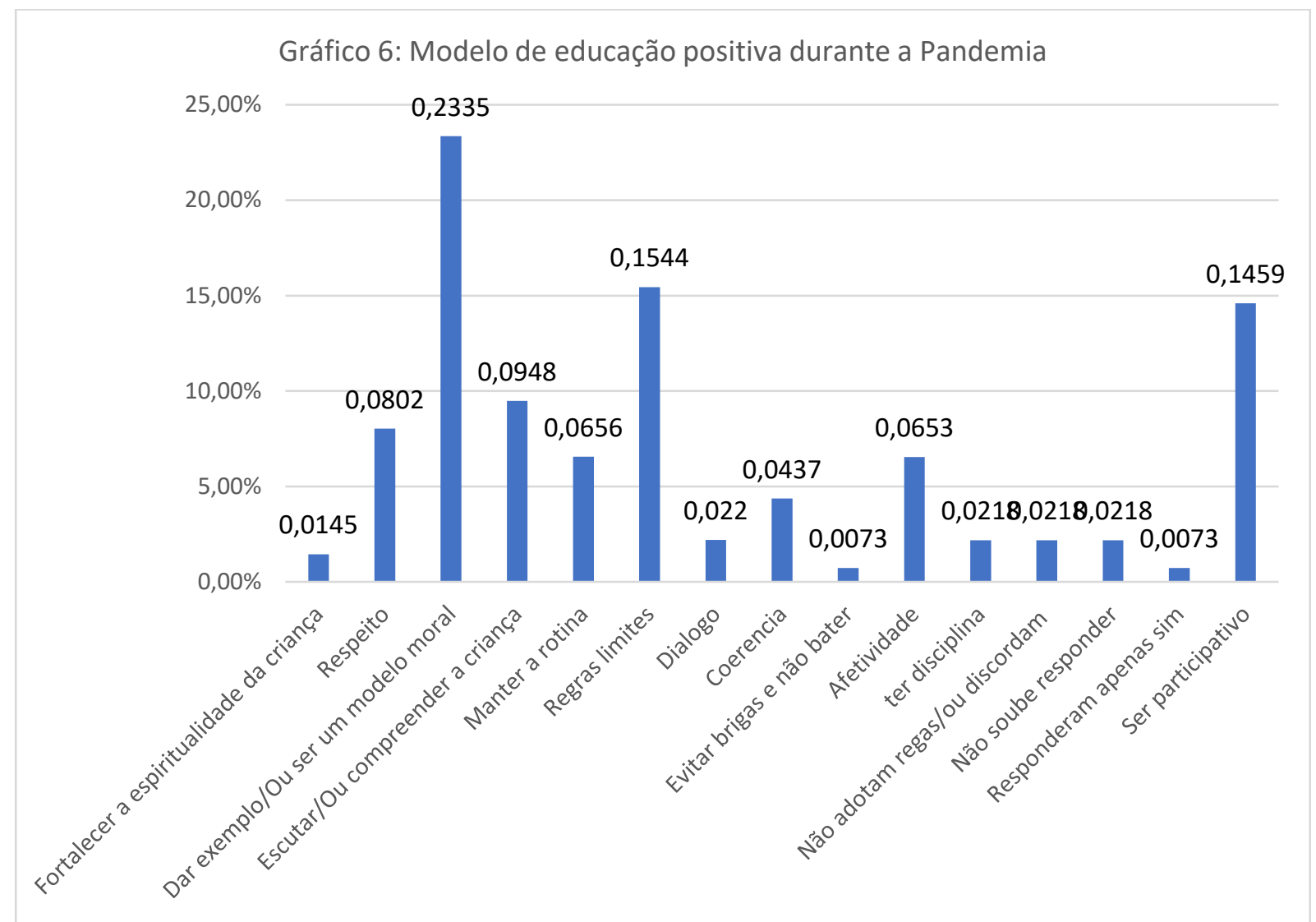

Fonte: (CARVALHO, LEITE e SOUZA, 2021).

No gráfico 6 , nota-se que com o maior resultado que os adultos comungam da ideia de que o exemplo e/ou ser um modelo moral é determinante para a educação positiva das crianças e remete ao seu possível comportamento de serem adultos que pela maneira que se portam pretendem que as crianças internalizem suas posturas, porém precisa sempre problematizar se os cuidadores parentais entendem quais modelos morais podem ser prejudiciais, mas isso envolve seu mundo de crenças do que é certo e errado que também é marcado pela cultura de cada família. Então,

Para uma criança pequena, é natural imitar as pessoas mais próximas. Isto é uma forma de aprendizado. A criança pequena imita sem pensar sobre as consequências de seu comportamento. Os filhos estão o tempo todo nos observando, mesmo quando achamos que estão distraídos brincando com outra coisa. Isso é um dos princípios fundamentais do comportamento, ou seja, as pessoas, especialmente os filhos, aprendem de acordo com modelos que observam nos outros e, principalmente, nos seus pais. (WEBER, 2017, p. 124)

A atitude de firmar regras e limites são um comportamento que os respondentes dessa pesquisa acreditam ser muito importante, e falar de regras e limites é também ter um olhar de flexibilidade por parte dos adultos que precisam entender sobre as limitações 
que o cérebro das crianças devido ao seu desenvolvimento, principalmente quando se fala de primeira infância. Assim,

As regras devem ser coerentes, razoáveis para a idade da criança e incorporar um certo grau de tolerância para com a infância! Por exemplo, levar a criança para brincar no parque ou à casa da vovó onde tem um quintal enorme e dizer que ela não deve sujar a roupa não é possível! Limites também têm de ter limite! Falar o tempo todo e limitar tudo faz com que a criança não respeite mais e aprenda a fugir, mentir, esconder o que está fazendo. (WEBER, 20177, p. 98)
E para entrelaçar toda a discussão com o tema sobre os estilos parentais pode-se afirmar que $71,3 \%$ dos respondentes, como pode ser visto no gráfico 7 abaixo, disseram pertencer ao estilo autoritativo ou participativo que é o mais adequado e valorizado pela educação positiva, indicando que grande parte desses pais estão possivelmente no caminho mais assertivo, entretanto deve-se mencionar que esses dados não devem ser compreendidos como verdades absolutas, pois, é sabido que para se considerar pertencente a determinado estilo parental envolve um autoconhecimento dos adultos e sabe-se que muitos não refletem sobre suas posturas reais com as crianças.

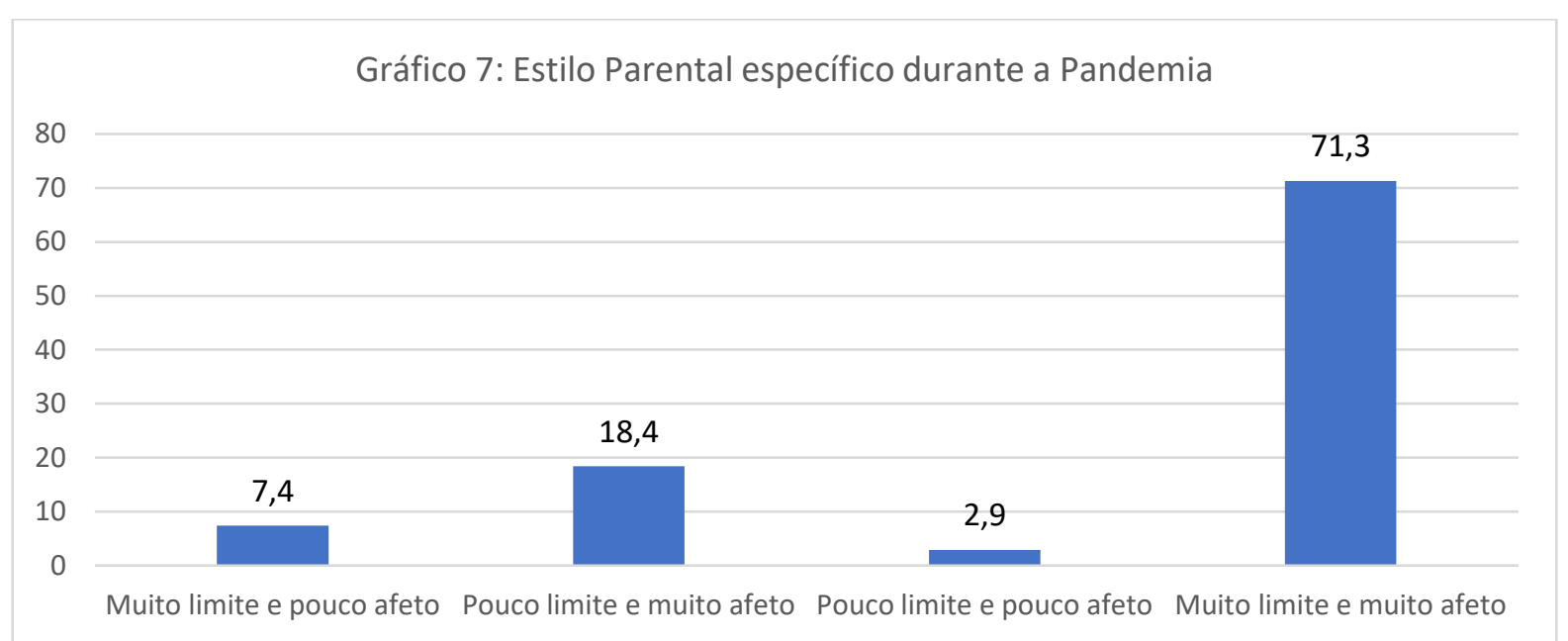

Fonte: (CARVALHO, LEITE e SOUZA, 2021).

Em relação ao comportamento dos adultos e aos seus respectivos estilos parentais, antes de qualquer passo é importante que esses adultos enxerguem o que faz evocar determinado comportamento seu para com seus filhos, e esse processo autorreflexivo poerá ajudar na sua própria saúde emocional. Então,
Entender melhor o funcionamento do cérebro ajuda a pessoa a parar com os autojulgamentos constantes e a adquirir mais autoaceitação. Entrar em, estados de autorreflexão requer períodos de solidão, o que é bem difícil para quem tem crianças pequenas, (SIEGEL; HARTZZELL, 2020, p. 204).

Sabe-se que cada adulto terá um estilo parental específico para adotar no 
cotidiano com a sua criança, mas é importante que para além da compreensão que deve-se ter acerca do cérebro da criança, os adultos também têm suas necessidades e precisam se enxergarem com amor e compreensão.

\section{CONSIDERAÇÕES FINAIS}

Depreende-se que os cuidadores parentais desse estudo, em sua grande maioria, demonstram que valorizam a ideia de modelo moral e acreditam que os pais são modelos morais que determinam muitos aspectos da identidade infantil. Um número considerável de respondentes também afirmou gostar de adotar uma rotina com as crianças e dizem pertencer ao estilo parental autoritativo. Porém, é importante perceber que os apontamentos de alguns respondentes, possibilitaram aos pesquisadores, compreender que estes pais, se afastam dos conceitos da educação positiva ou disciplina positiva. Exemplo disso, sãos os genitores que não adotam regras e negligenciam o tempo de qualidade junto às crianças. Mesmo se mostrando aptos a validar as emoções dos filhos, há muitos pontos que ainda precisam ser melhorados para que, de fato esses pais possam ser considerados do estilo parental autoritativo. Com base nesse entendimento, foi possível compreender que, mesmo diante de dificuldades, outra grande parcela de pais, têm contribuído para que as crianças da Educação Infantil aprendam durante o ensino remoto, pois esses adultos criaram meios de potencializar essa aprendizagem, através da afetividade, participação, regras, dentre outras posturas.

Quanto às crianças, foi perceptível observar, por meio das respostas dos pais, que cada uma respondeu de uma forma específica ao ensino remoto, e esse dado é importante para reafirmar que ao se lançar à infância é preciso que essa fase seja sempre entendida em sua pluralidade, e a estrutura do rizoma serve de exemplo para falar-se na fluidez e possibilidades que ser criança marca nas relações com o mundo. Então, a aprendizagem da criança será marcada pela sua singularidade e suas dificuldades, sendo determinada por fatores externos como postura parental e pela atitude do professor no processo de inclusão. Deve-se destacar que essa pesquisa inaugura de modo problematizador, as possibilidades de se tomar o diálogo acerca do ensino remoto a partir da percepção dos pais de crianças pequenas sobre seu estilo parental durante a atual pandemia.

\section{REFERÊNCIAS}

BARDIN, L. Análise de conteúdo. Tradução: Luís Antero Reto, Augusto Pinheiro - São Paulo: Edições 70, 2016.

BAUMRIND, D. Effects of authoritative parental control on child behavior. Child Development, Chicago, v. 37, n. 4, p. 887-907, 1966.

CARTAXO, V. A. B. Operação pais sempre. Uma missão que não pode parar. Novo Hamburgo, RS: Sinopsys, 2016.

DARLING, N.; STEINBERG, L. Parenting style as context: an integrative model. Psychological Bulletin, Washington, v. 113, n. 2, p. 487-496, 1993.

LEITE, C. R. Estilos de Liderança de Professores: Conhecer para Compreender. Editora Appris, 2018.

LINS, T. C. D. S. Práticas educativas maternas e problemas internalizantes em pré-escolares. 2014. Disponível em:

<https://repositorio.ufba.br/ri/handle/ri/14512>. Acesso em: 10 mar. 2017. 
MACCOBY, E.; MARTIN, J. Socialization in the context of the family: parent-child interaction. In: HETHERINGTON, E. M.; MUSSEN, P. H. (Org.). Handbook of child psychology: socialization, personality, and social development. New York: Wiley, 1983. v. 4, p. 1-101.

NELSEN, J. Disciplina positiva. O guia clássico para pais e professores que desejam ajudar as crianças a desenvolver autodisciplina, responsabilidade, cooperação e habilidades para resolver problemas. Edição digital. 2016

PROBST, M. A criança entre dois mundos - Mundo disciplinar e mundo rizomático. Diponível em: https://anped.org.br/news/ix-seminario-anped-sul2012 Acesso em: 20 de novembro de 2020.

Secretaria de Estado da Educação. Manual de orientações pedagógicas para o atendimento remoto da educação infantil. In: Brasília. 2020.

SIDMAN, M. Coerção e suas implicações. Campinas: Livro Pleno, 1995.

SIEGEL, D. J; BRYSON, T. P. O cérebro da criança. 12 estratégias revolucionárias para treinar o cérebro em desenvolvimento do seu filho. São Paulo: nVersos, 2015.

SIEGEL, D. J; HARTZELL, M. Parentalidade consciente. Como o autoconhecimento nos ajuda a criar nossos filhos. São Paulo: nVersos, 2020.

WEBER, L. N. Eduque com Carinho. Equilíbrio entre amor e limites. 6. ed. rev. e atual. Curitiba, PR: Juruá, 2017

\section{NOTA}

Os (as) autores (as) foram responsáveis pela concepção do artigo, pela análise e interpretação dos dados, pela redação e revisão crítica do conteúdo do manuscrito e, ainda, pela aprovação da versão final publicada. 


\section{Perception of parents of young children about Remote Teaching and the Parenting Style assumed during the COVID-19 pandemic}

\section{ABSTRACT}

The following research is the result of a study conducted with parental caregivers of children in early childhood age who are currently enrolled in early childhood education. This study is marked by the Parenting Styles Theory directed to respondents through school institutions and has like main goal to understand the perception of parents of young children about Remote Teaching and Parenting Style during the current pandemic. An online questionnaire was adopted for data collection and included thirty nine questions addressed to parental caregivers, which were inspired by the twelve principles of Positive Education and counted as a sample of one hundred thirty six adults respondents. The data analysis was built based on the Content Analysis that causes the construction of a study that prioritizes the categorization and organization of the data, which are crucial for the structuring of results. The discussion of the data takes into account the following categories were chosen: Teachers, Involvement of parental caregivers, child as a rhizomatic structure and behavior of adults. The Covid-19 pandemic launched challenges to adults (teachers and parental caregivers), and both had their duties multiplied by the overhead that remote education brought, teachers demonstrate a firm and gentle education from the perspective of parents, while the family needs to invest more in rules and using quality time with their children.

Keywords: Parenting styles. Early Childhood Education. Remote education.

\section{Percepción de los padres de niños pequeños sobre la enseñanza remota y el estilo de crianza asumido durante la pandemia COVID-19}

\section{RESUMEN}

La siguiente investigación es resultado de un estudio realizado con cuidadores parentales de niños en la primera infancia y que actualmente están matriculados en la educación infantil, este estudio se caracteriza por la Teoría de los Estilos Parentales dirigida a los encuestados a través de las instituciones escolares y tiene como meta principal comprender la percepción de los padres de niños pequeños sobre la Enseñanza Remota y el Estilo de Crianza durante la actual pandemia. Para la recopilación de datos se adoptó un cuestionario en línea, que incluía treinta y nueve preguntas dirigidas a los cuidadores parentales, inspiradas en los doce principios de la educación positiva, y que incluía a ciento treinta y seis adultos como muestra de los encuestados. El análisis de datos se construyó basándose en el Análisis de Contenido, que causa la construcción de un estudio que prioriza la categorización y organización de los datos, que resultan ser cruciales para la estructuración de los hallazgos. Para el debate de los datos, se eligieron como categorías de análisis: Profesores, Participación cuidadores parentales, Niño como estructura rizomática y Comportamiento adulto. La pandemia de Covid-19 lanzó desafíos a los adultos (maestros y cuidadores parentales), y ambos tuvieron sus asignaciones multiplicadas por la sobrecarga que trajo la enseñanza a distancia, los maestros demostraron una educación firme y amable desde la perspectiva de los padres, mientras que la familia necesita invertir más en reglas y en el uso de tiempo de calidad con sus hijos.

Palabras clave: Estilos parentales. Educación Infantil. Enseñanza remota. 